\title{
EFEITO DA REVEGETAÇÃO E DA ADUBAÇÃO DE ÁREA DEGRADADA NA PRODUÇÃO DE MATÉRIA SECA E NA ABSORÇÃO DE NUTRIENTES ${ }^{1}$
}

\author{
NERILDE FAVARETTO², ANÍBAL DE MORAES ${ }^{3}$, \\ ANTÔNIO CARLOS VARGA MOTTA ${ }^{2}$ e BEATRIZ MONTE SERRAT PREVEDELLO ${ }^{3}$
}

\begin{abstract}
RESUMO - A produção de matéria seca, a concentração e a extração de macronutrientes pela planta foram avaliados em área degradada pela mineração do xisto, após sua revegetação com espécies forrageiras submetidas a diferentes adubações. $\mathrm{O}$ experimento foi conduzido durante 12 meses, no município de São Mateus do Sul, PR, e o delineamento foi de blocos ao acaso, com parcelas subdivididas, envolvendo três parcelas referentes às adubações, e três subparcelas com as forrageiras, totalizando 36 unidades experimentais. As adubações utilizadas foram: I - adubação mineral com permanência da parte aérea; II - adubação mineral e orgânica com exportação da parte aérea; III - adubação mineral com exportação da parte aérea. As forrageiras constituíram diferentes sistemas, da seguinte forma: Sistemas I e II - gramíneas e leguminosas perenes de inverno e verão; Sistema III - gramíneas e leguminosas anuais de inverno e verão. As avaliações realizadas foram quanto ao peso de matéria seca e à concentração e extração pela planta de $\mathrm{P}, \mathrm{K}, \mathrm{Ca}, \mathrm{Mg}, \mathrm{C}$ e N. Conclui-se, no que se refere ao período de estudo, que as maiores produções de matéria seca ocorreram na adubação orgânica e nas forrageiras anuais, e que a extração dos nutrientes pela planta, de maneira geral, foi superior nos tratamentos com maior produção de matéria seca.
\end{abstract}

Termos para indexação: solo degradado, recuperação, nutriente, forrageira.

\section{EFFECT OF REVEGETATION AND OF FERTILIZATION OF DEGRADED AREA ON PRODUTION OF DRY MATTER AND ON NUTRIENT UPTAKE}

\begin{abstract}
This work was carried out on degraded area by oil shale mining, to evaluate the effect of different fertilizations and revegetations with forage species on the total dry production and the macronutrients concentration and extraction by plants. The experiment was conducted for 12 months at São Mateus do Sul, Paraná State, Brazil, in a randomized block with split plots design, being three plots related to fertilization and three subplots related to forage species. The fertilizations used were: I - mineral fertilizer with aerial part left over; II - mineral and organic fertilizer with aerial part removed; III - mineral fertilizer with aerial part removed. Forage composed the following systems: Systems I and II - perennial grasses and legumes species of summer and winter; System III - annual grasses and legumes species of summer and winter. The evaluations were related to dry matter and concentration and extraction by plant of $\mathrm{P}, \mathrm{K}, \mathrm{Ca}, \mathrm{Mg}, \mathrm{C}$ and $\mathrm{N}$. It was observed greatest dry matter production in the treatment with organic fertilization and with annual forages, and that the extraction of nutrients by plants was, in general, superior in treatments with high dry matter production.
\end{abstract}

Index terms: degraded area, reclamation, nutrient, forage.

${ }^{1}$ Aceito para publicação em 28 de abril de 1999. Extraído da Dissertação de Mestrado do primeiro autor, apresentada à Universidade Federal do Paraná (UFPR).

${ }^{2}$ Eng. Agrôn., M.Sc., Dep. de Solos, UFPR, Rua dos Funcionários, 1540, Juveve, Caixa Postal 2959, CEP 80035-050 Curitiba, PR. E-mail: nerilde@purdue.edu

${ }^{3}$ Eng. Agrôn., Dr., Dep. de Fitotecnia e Fitossanitarismo, UFPR. E-mail: anibalm@agrarias.ufpr.br

\section{INTRODUÇÃO}

A produção de matéria seca dos vegetais depende da eficiência fotossintética, e esta é determinada pela espécie, temperatura, suprimento de água e nutrientes, radiação solar e práticas de manejo. O solo e o clima são os fatores mais determinantes na distri- 
buição e produção de plantas, porém, as espécies forrageiras adaptam-se a diversas situações. Em muitas partes do mundo, as forrageiras são cultivadas em solos íngremes, erodíveis, inférteis ou áridos, que não sustentam culturas graníferas. Algumas espécies forrageiras são capazes de crescer em solos nessas condições, no entanto, respondem favoravelmente a boas práticas de manejo, e as adubações, de maneira geral, oferecem oportunidades de melhores produtividades (Fageria et al., 1991).

Melo (1994) verificou o efeito da adubação mineral na produção de matéria seca de diferentes forrageiras em área degradada. Todas as espécies, isoladas ou em associação, responderam à adubação de NPK, sendo as maiores produções ocorridas nos tratamentos com as maiores dosagens. Lucchesi (1988) observou diferenças significativas entre as sucessões de culturas forrageiras na produção de matéria seca em área degradada, e Motta Neto (1995) verificou que, independentemente das espécies, as maiores produções de matéria seca de forrageiras em área degradada foram observadas nos tratamentos com adubação mineral + orgânica.

A concentração de nutrientes em plantas, expressa com base na matéria seca, é afetada por vários fatores, incluindo espécies e cultivar, idade e órgão da planta, interação com outros nutrientes e fatores ambientais, como precipitação, temperatura e luminosidade (Fageria et al., 1991). Conforme Malavolta et al. (1989), quanto maior a disponibilidade de nutrientes no solo, maior será a absorção pela planta.

Malavolta et al. (1986) compararam a composição mineral média de gramíneas e leguminosas cultivadas em São Paulo, e verificaram teores semelhantes de $\mathrm{K}$, ao passo que os teores de N, P, Ca e $\mathrm{Mg}$ foram superiores nas leguminosas, com diferenças evidentes nas concentrações de $\mathrm{N}$ e $\mathrm{Ca}$. Nos resultados apresentados por Spears (1994), os teores médios de $\mathrm{P}, \mathrm{Ca}$ e $\mathrm{Mg}$, bem como de $\mathrm{K}$, foram superiores nas leguminosas, comparados com os das gramíneas.

A quantidade de nutrientes extraídos pela cultura depende da concentração destes na planta, e da produtividade (Mengel \& Kirkby, 1987). Nas condições de pastoreio, as quantidades de nutrientes exportados são relativamente pequenas, devido ao flu- xo destes no sistema solo-planta-animal. Entretanto, as remoções tornam-se consideráveis quando se faz o corte e exportação da forrageira (Malavolta et al., 1986). As remoções de N, P, K, Ca, Mg e S por forrageiras em condições brasileiras são mostradas por Fageria et al. (1991), e, de maneira geral, o N e $\mathrm{K}$ foram os elementos removidos em maior quantidade.

Num programa de recuperação de ambientes degradados, vários tipos de revegetação podem ser planejados, dependendo, basicamente, das potencialidades locais e dos objetivos a serem atingidos (Andrade, 1991). As espécies forrageiras, gramíneas e leguminosas, além de serem fundamentais à nutrição dos animais, constituem recursos essenciais ao melhoramento e conservação do solo (Medeiros et al., 1987). Práticas como calagem e adubação são também necessárias para o melhor desenvolvimento dessas espécies.

Este trabalho teve por objetivo avaliar o efeito de diferentes adubações e espécies forrageiras na produção de matéria seca e na concentração e extração dos macronutrientes pela planta.

\section{MATERIAL E MÉTODOS}

O experimento foi conduzido durante 12 meses, no município de São Mateus do Sul, PR, em área reconstituída após a mineração do xisto, e representa uma continuidade dos estudos na linha de pesquisa com forrageiras e adubações na recuperação de solo degradado, iniciados nessa área em 1986. O delineamento foi o de blocos ao acaso, com parcelas subdivididas envolvendo três parcelas referentes às adubações, e três subparcelas com as forrageiras, totalizando 36 unidades experimentais. As adubações consistiam de: I - adubação mineral com permanência da parte aérea (MIN+PA); II - adubação mineral e orgânica com exportação da parte aérea (MIN+ORG-PA); III - adubação mineral com exportação da parte aérea (MIN-PA). As forrageiras foram: Sistema I - gramíneas e leguminosas perenes (pensacola, trevo-branco, trevo-vermelho, e cornichão); Sistema II - gramíneas e leguminosas perenes (hemártria, trevo-branco, trevo-vermelho, e cornichão); Sistema III - gramíneas e leguminosas anuais (azevém, ervilhaca-peluda e trevo-vesiculoso, no inverno; sorgo e crotalária, no verão).

A área recebeu $3.000 \mathrm{~kg} \mathrm{ha}^{-1}$ de calcário (calxisto com $40 \%$ PRNT). A quantidade de fertilizante mineral aplicado foi $44 \mathrm{~kg} \mathrm{ha}^{-1}$ de N, $160 \mathrm{~kg} \mathrm{ha}^{-1}$ de $\mathrm{P}_{2} \mathrm{O}_{5}$ e $150 \mathrm{~kg} \mathrm{ha}^{-1} \mathrm{de}$ 
$\mathrm{K}_{2} \mathrm{O}$, na forma de uréia, superfosfato triplo e simples e cloreto de potássio, respectivamente, metade no plantio das forrageiras de inverno, e o restante, no plantio das forrageiras de verão. Tanto o corretivo como os adubos foram distribuídos a lanço, sem incorporação. As parcelas com adubo orgânico receberam $13.160 \mathrm{~kg} \mathrm{ha}^{-1}$ por ano (matéria seca) de esterco bovino ( $19 \mathrm{~g} \mathrm{~kg}^{-1} \mathrm{de} \mathrm{N} ; 5 \mathrm{~g} \mathrm{~kg}^{-1}$ de P; $14 \mathrm{~g} \mathrm{~kg}^{-1}$ de $\mathrm{K} ; 10 \mathrm{~g} \mathrm{~kg}^{-1}$ de Ca e $5 \mathrm{~g} \mathrm{~kg}^{-1}$ de $\mathrm{Mg}$ na matéria seca), que, assim como o fertilizante mineral, foi distribuído a lanço superficialmente, no plantio das forrageiras de inverno e verão. Além do $\mathrm{N}$ aplicado no plantio, efetuaram-se adubações de cobertura $\left(80 \mathrm{~kg} \mathrm{ha}^{-1}\right.$ de uréia), distribuídas durante o ano de cultivo.

$\mathrm{O}$ estabelecimento das forrageiras, exceto das gramíneas perenes de verão, que já estavam estabelecidas, foi feito por semeadura a lanço, sem revolvimento do solo. O plantio das forrageiras perenes e anuais de inverno ocorreu em maio/93, e as anuais de verão, em dezembro/94. No plantio das anuais de verão foram abertos sulcos, com espaçamento de $50 \mathrm{~cm}$, onde consorciou-se crotalária e sorgo, em linhas alternadas.

Os dados de produção de matéria seca resultaram do corte total da subparcela (considerando $90 \mathrm{~cm}$ de bordadura) na fase de florescimento. No período estudado (maio/94 a maio/95) obtiveram-se quatro cortes nas culturas perenes, e dois cortes nas culturas anuais, sendo dois cortes coincidentes entre perenes e anuais. A produção total de matéria seca foi obtida a partir do somatório das coletas individuais. Para análise química da planta, foram amostrados 15 pontos de cada subparcela, na estação de inverno (outubro/94) e na estação de verão (março/95). Essa amostragem ocorreu juntamente com o corte total das forrageiras perenes e anuais na fase de florescimento, respeitando os limites da área útil. As amostras da planta para análise química foram lavadas com água desionizada, secadas em estufa a $60^{\circ} \mathrm{C}$, moídas, peneiradas a $1 \mathrm{~mm}$, e acondicionadas em frascos. Os nutrientes $\mathrm{P}$, $\mathrm{K}, \mathrm{Ca}$ e $\mathrm{Mg}$ foram extraídos por meio de digestão por via seca, sendo $\mathrm{Ca}$ e $\mathrm{Mg}$ determinados por espectrofotometria de absorção atômica, K por fotometria de chama, e P por colorimetria segundo metodologia de Hildebrand (1977). Os teores de $\mathrm{N}$ e $\mathrm{C}$ foram determinados pelos métodos de Kjeldahl (Hildebrand, 1977) e Walkley-Black (Tedesco et al., 1985), respectivamente. Para a digestão do C, as amostras foram moídas novamente, até passar pela peneira de $0,3 \mathrm{~mm}$. Os resultados da extração dos nutrientes foram obtidos pela multiplicação dos teores na planta com a produção de matéria seca, em suas respectivas coletas, sendo então somados para obtenção da extração total do período (maio/94 a maio/95). Obtiveram-se, no total, quatro cortes das espécies perenes, para avaliação da produ- ção total, e somente duas coletas para determinação dos nutrientes, portanto, foram multiplicadas as produções de dezembro/94 e janeiro/95, cujos nutrientes não foram analisados pelos teores de nutrientes obtidos em outubro/94 e março/95, respectivamente.

Por meio da análise de variância para o modelo de parcelas subdivididas e à comparação de médias pelo teste de Tukey a $5 \%$ de probabilidade, avaliou-se o efeito de espécies forrageiras e adubações na produção de matéria seca total e extração de nutrientes pela planta.

\section{RESULTADOS E DISCUSSÃO}

\section{Produção de matéria seca}

Os melhores resultados de produção de matéria seca total foram obtidos nas parcelas com adubação orgânica (Fig. 1) o que está de acordo com os resultados de Lucchesi (1988) e Motta Neto (1995). A maior disponibilidade dos nutrientes no solo, com exceção do K, em tratamentos com adubação orgânica, pode ter resultado em maior produção de matéria seca. Dados de fertilidade do solo relacionados a este experimento encontram-se em Favaretto et al. (2000). Melo (1994) verificou que as espécies forrageiras, isoladas ou em associação, responderam à adubação de NPK, sendo as maiores produções correspondentes às maiores dosagens.

Com relação às forrageiras (Fig. 2), verifica-se maior produção de matéria seca total no Sistema III, apesar de essas espécies anuais fornecerem apenas dois cortes no total. Entre as espécies perenes, o Sistema II foi superior ao Sistema I, o que caracteriza a diferença do potencial produtivo da hemártria e pensacola, ambas gramíneas perenes de verão. Nesta mesma área experimental, Lucchesi (1988) também constatou diferença entre associações de forrageiras, sendo as gramíneas anuais, consorciadas, ou não, com leguminosas, superiores às perenes; no entanto, Motta Neto (1995) não obteve diferença entre as forrageiras.

As produções de matéria seca obtidas nos Sistemas I e II (6.075 e $7.971 \mathrm{~kg} \mathrm{ha}^{-1}$, respectivamente) e no Sistema III ( $1.610 \mathrm{~kg} \mathrm{ha}^{-1}$ nas culturas de inverno e $7.490 \mathrm{~kg} \mathrm{ha}^{-1}$ nas espécies de verão), de maneira geral, apresentam valores equivalentes às produções de experimentos em áreas não degradadas, conforme Machado \& Machado (1982), Sá (1984), Postiglioni 
(1985). Apesar das condições adversas, essas espécies, principalmente as gramíneas perenes, mostram grande potencial produtivo em solos degradados em processo de recuperação, desde que sejam realizadas a correção de acidez e a adubação com NPK.

\section{Extração de nutrientes pela planta}

A extração de K (Fig. 3) nos Sistemas I e III foi maior no tratamento com adubação orgânica, devido à maior produção de matéria seca neste tratamento, conforme descrito anteriormente (Fig. 1). No Sis-

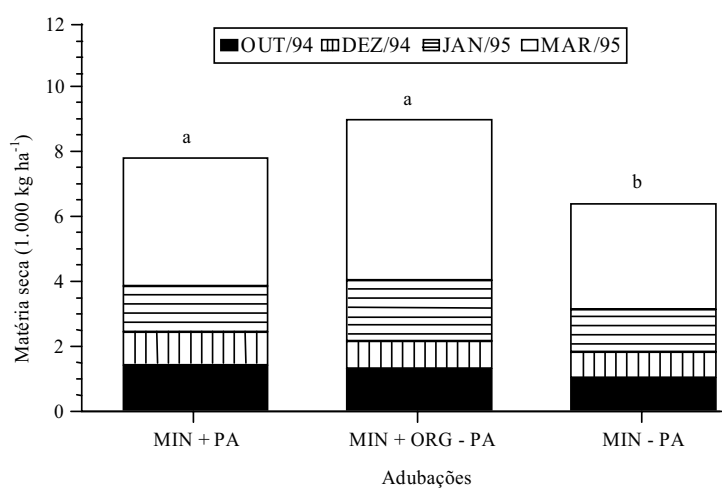

FIG. 1. Efeito das adubações na produção de matéria seca total e parcial. Período maio/94 a maio/95. (Médias com mesma letra não diferem significativamente pelo teste de Tukey a $5 \%$ de probabilidade).

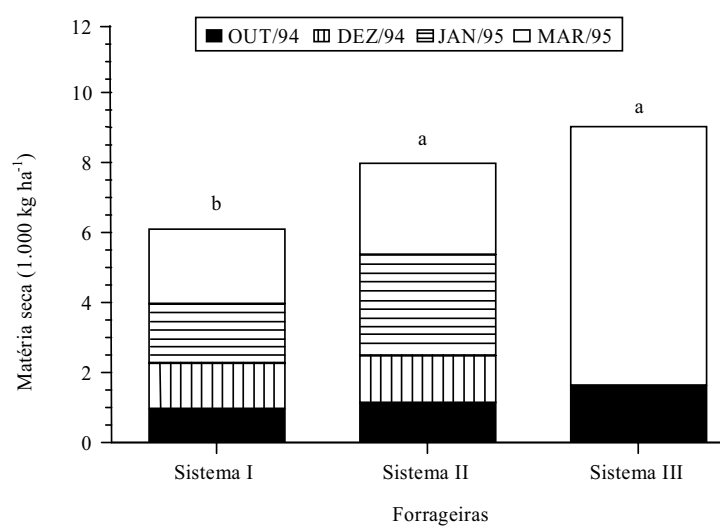

FIG. 2. Efeito das forrageiras na produção de matéria seca total e parcial. Período maio/94 a maio/95. (Médias com mesma letra não diferem significativamente pelo teste de Tukey a $5 \%$ de probabilidade). tema II, apesar de não significativo estatisticamente, o tratamento com permanência da parte aérea apresentou maior extração; isto mostra que a concentração de K no tecido vegetal (Tabela 1) teve maior efeito que a produção de matéria seca. Neste tratamento, o K do solo apresentou um elevado teor no Sistema II, justificando maior absorção pela planta e, conseqüentemente, maior concentração no tecido vegetal. É interessante salientar que a extração de K pela planta mostrou correlação significativa com a produção de matéria seca, apresentando um r de 0,67.

A diferença entre a permanência e a exportação da parte aérea não foi observada no Sistema I, sendo tal comportamento diferente ao da produção de matéria seca (Fig. 1). Nesse sistema, a concentração do K na planta (Tabela 1) foi menor na adubação mineral com permanência da parte aérea, determinando a extração desse nutriente.

Em relação às forrageiras, observa-se que o Sistema II apresentou maiores extrações em todas as adubações, apesar da menor produção de matéria seca, em comparação com o Sistema III (Fig. 2). A concentração média do $\mathrm{K}$ no tecido vegetal foi de $21,9 \mathrm{~g} \mathrm{~kg}^{-1}$, enquanto no Sistema III foi equivalente a $16,4 \mathrm{~g} \mathrm{~kg}^{-1}$. De modo geral, a extração foi diretamente proporcional à produção de matéria seca, mas a ex-

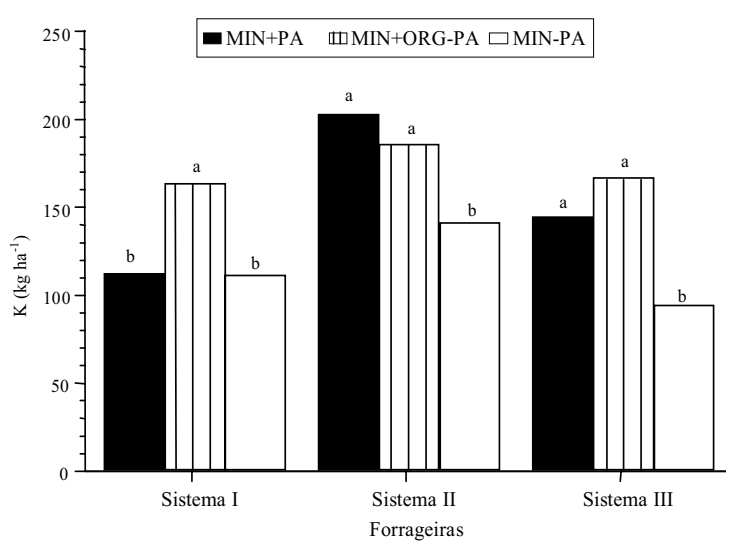

FIG. 3. Efeito das adubações e forrageiras na extração de K pela planta. Período maio/94 a maio/95. (Médias com mesma letra dentro de cada sistema forrageiro não diferem significativamente pelo teste de Tukey a $5 \%$ de probabilidade). 
tração em alguns sistemas forrageiros foi determinada pela concentração do nutriente no tecido vegetal.

Alterações na extração de nutrientes ocorrem em função principalmente da espécie e práticas de manejo. Neste experimento a quantidade de K extraída pela parte aérea variou de 94 a $203 \mathrm{~kg} \mathrm{ha}^{-1}$. Fageria et al. (1991) apresentaram extrações de K em forrageiras gramíneas e leguminosas, cujos valores máximos e mínimos encontrados foram equivalentes a 108 e $504 \mathrm{~kg} \mathrm{ha}^{-1}$, enquanto Haag \& Dechen (1994) mostram extrações de 15 a $1.009 \mathrm{~kg} \mathrm{ha}^{-1}$.

Com relação ao $\mathrm{Ca}$ (Fig. 4), observam-se maiores extrações na adubação orgânica dos Sistemas II e III. Tais resultados ocorreram principalmente devido à maior produção de matéria seca e pela maior concentração desse nutriente no tecido da planta, provavelmente em função dos teores no solo. A correlação com a produção de matéria seca foi significativa, mostrando $r$ de 0,78 .

No Sistema I, observa-se comportamento diferente ao da produção de matéria seca e dos teores no solo, sendo influenciado por outros fatores que interferem na concentração de nutrientes, e, conseqüentemente, na extração pela planta. Nesse sistema, a concentração no tecido vegetal (Tabela 1) do tratamento com exportação da parte aérea foi superior às demais adubações, e portanto, determinou a extração de nutrientes. Apesar de ser o mesmo sistema, a composição botânica variou entre as adubações, prevalecendo espécies leguminosas principalmente no $1^{\mathrm{o}}$ corte. Segundo Spears (1994), a concentração de Ca em plantas leguminosas é superior à das gramíneas. No entanto, além da espécie, outros fatores interferem no teor de nutrientes em plantas, incluindo idade da planta e interação com íons (Fageria et al., 1991). Segundo Mengel \& Kirkby (1987), os cátions Mg, K e $\mathrm{Na}$ competem com o $\mathrm{Ca}$ no processo de absorção pela planta.

Com relação às forrageiras, observa-se que os sistemas de maior produção de matéria seca (II e III) apresentaram maior extração do $\mathrm{Ca}$, com exceção do tratamento com exportação da parte aérea. Nesse tratamento o Sistema I foi superior aos demais, apesar de apresentar menor produção. Tal comportamento deve-se à maior concentração de $\mathrm{Ca}$ no tecido vegetal, conforme já discutido.

$\mathrm{O} \mathrm{Mg}$ foi extraído em maior quantidade na adubação orgânica (Fig. 5) e no Sistema III (Fig. 6), o que caracteriza que a produção de matéria seca determinou a extração desse nutriente. Os tratamentos que apresentaram as maiores extrações foram os que produziram mais matéria seca, sendo a correlação entre produção e extração significativa e equivalente a 0,83 .

TABELA 1. Concentração média em $\left(\mathrm{g} \mathrm{kg}^{-1}\right)$ de $\mathrm{N}, \mathrm{P}, \mathrm{K}, \mathrm{Ca}, \mathrm{e} \mathrm{Mg}$ da parte aérea (planta inteira) dos cortes efetuados em outubro/94 e março/95 nas diferentes forrageiras e adubações.

\begin{tabular}{llllllll}
\hline Forrageira $^{1}$ & Adubação & $\mathrm{C}$ & $\mathrm{N}$ & $\mathrm{P}$ & $\mathrm{K}$ & $\mathrm{Ca}$ & $\mathrm{Mg}$ \\
\hline Sistema I & MIN+PA & 425,1 & 13,5 & 2,5 & 11,9 & 4,6 & 2,4 \\
Sistema I & MIN+ORG-PA & 424,3 & 14,4 & 2,8 & 22,7 & 4,5 & 2,5 \\
Sistema I & MIN-PA & 422,5 & 16,8 & 2,7 & 20,9 & 6,9 & 2,9 \\
\hline Sistema II & MIN+PA & 421,9 & 11,4 & 2,3 & 23,0 & 4,0 & 2,1 \\
Sistema II & MIN+ORG-PA & 423,2 & 13,6 & 2,8 & 21,1 & 4,9 & 3,4 \\
Sistema II & MIN-PA & 422,5 & 14,1 & 2,4 & 21,6 & 5,5 & 2,9 \\
\hline Sistema III & MIN+PA & 427,1 & 13,7 & 2,4 & 17,0 & 4,5 & 2,6 \\
Sistema III & MIN+ORG-PA & 431,6 & 16,7 & 2,5 & 17,6 & 5,1 & 2,9 \\
Sistema III & MIN-PA & 427,9 & 13,0 & 2,2 & 14,8 & 4,9 & 2,9 \\
\hline
\end{tabular}

1 Sistema I - gramíneas e leguminosas perenes (pensacola, trevo-branco, trevo-vermelho, e cornichão); Sistema II - gramíneas e leguminosas perenes (hemártria, trevo-branco, trevo-vermelho, e cornichão); Sistema III - gramíneas e leguminosas anuais (azevém, ervilhaca-peluda e trevo-vesiculoso, no inverno; sorgo e crotalária, no verão). 
Neste experimento, a extração de $\mathrm{Ca}$ variou de 26 a $49 \mathrm{~kg} \mathrm{ha}^{-1}$ e de $\mathrm{Mg}$ de 14 a $35 \mathrm{~kg} \mathrm{ha}^{-1}$. Haag \& Dechen (1994) mostraram extrações de 5 a $302 \mathrm{~kg} \mathrm{ha}^{-1}$ de Ca e de 1 até $83 \mathrm{~kg} \mathrm{ha}^{-1}$ de $\mathrm{Mg}$ dependendo da produção de matéria seca e da espécie forrageira.

O P (Fig. 5), da mesma forma que os demais nutrientes, foi extraído em maior quantidade na adubação

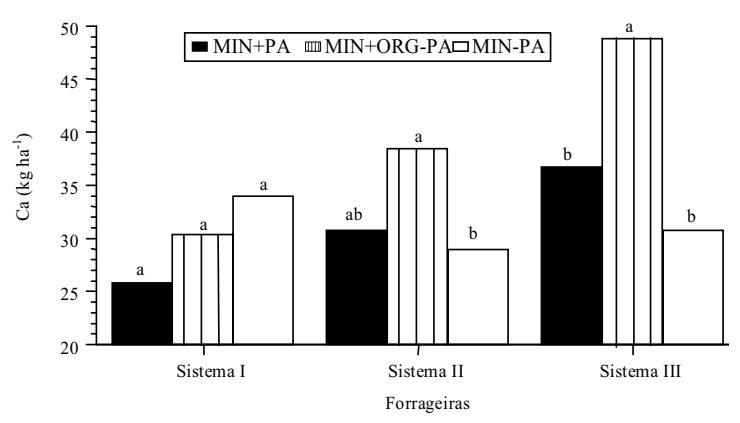

FIG. 4. Efeito das adubações e forrageiras na extração de Ca pela planta. Período maio/94 a maio/95. (Médias seguidas da mesma letra dentro de cada sistema forrageiro não diferem significativamente pelo teste de Tukey a $5 \%$ de probabilidade).

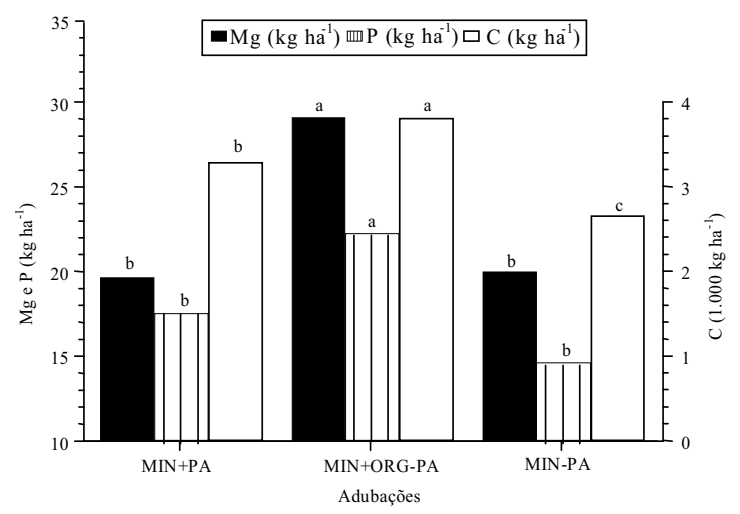

FIG. 5. Efeito das adubações na extração de $M g$ e P e na incorporação de $C$ pela planta. Período maio/94 a maio/95. (Médias seguidas da mesma letra dentro de cada nutriente não diferem significativamente pelo teste de Tukey a $5 \%$ de probabilidade). orgânica, porém não mostrou efeito das forrageiras, característica esta observada também no teor de $\mathrm{P}$ do solo. A maior produção de matéria seca e concentração na planta no tratamento com adubação orgânica, favoreceram as maiores extrações. A correlação entre extração de $\mathrm{P}$ e produção de matéria seca foi significativa e equivalente a 0,79 .

Nos sistemas forrageiros, a concentração do P na planta (Tabela 1) mostrou valores inversos ao da produção, caracterizando o efeito diluição; assim, as forrageiras com maiores produções apresentaram em média menores teores de nutrientes no tecido vegetal $\left(2,7 \mathrm{~g} \mathrm{~kg}^{-1}, 2,5 \mathrm{~g} \mathrm{~kg}^{-1}\right.$, e $2,4 \mathrm{~g} \mathrm{~kg}^{-1}$ nos Sistemas I, II e III respectivamente), e portanto, o efeito das forrageiras na extração não foi verificado.

As extrações de $\mathrm{P}$ neste experimento variaram de 14 a $25 \mathrm{~kg} \mathrm{ha}^{-1}$. Fageria et al. (1991) apresentaram extrações de 20 a $64 \mathrm{~kg} \mathrm{ha}^{-1}$, e Haag \& Dechen (1994), de 2 a $56 \mathrm{~kg} \mathrm{ha}^{-1} \mathrm{em}$ gramíneas e leguminosas forrageiras.

A extração de $\mathrm{N}$ (Fig. 7) também foi superior na adubação orgânica. Nos Sistemas II e III, observa-se que o tratamento com permanência da parte aérea foi superior ao da exportação, característica verificada também na produção de matéria seca. No entanto, o Sistema I mostrou valores inversos, em decorrência da maior concentração no tecido vege-

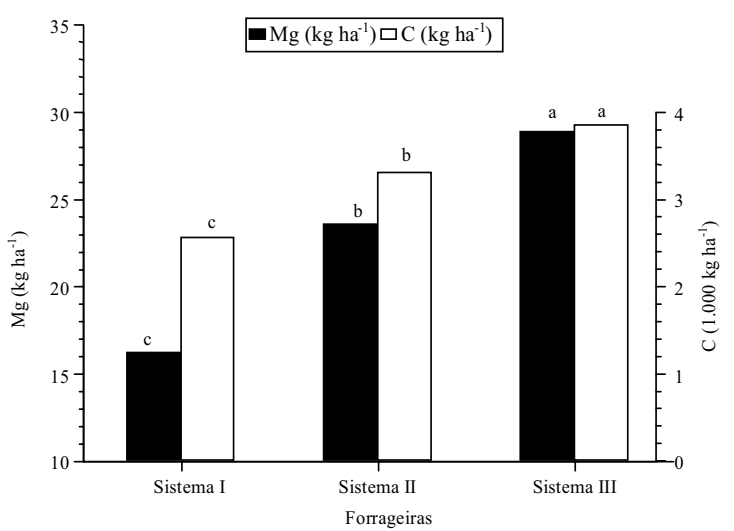

FIG. 6. Efeito das forrageiras na extração de Mg e incorporação de $\mathrm{C}$ pela planta. Período maio/94 a maio/95. (Médias seguidas da mesma letra dentro de cada nutriente não diferem significativamente pelo teste de Tukey a $5 \%$ de probabilidade). 
tal do tratamento com adubação mineral e exportação da parte aérea (Tabela 1). Apesar de ser o mesmo sistema forrageiro, diferenças na composição botânica foram observadas, prevalecendo nesse tratamento espécies leguminosas, e, de acordo com Malavolta et al. (1986) e Spears (1994), a concentração de $\mathrm{N}$ em plantas leguminosas é superior à das gramíneas.

Com relação às forrageiras, observa-se, na adubação com permanência da parte aérea e na adubação orgânica, o mesmo comportamento da produção de matéria seca; porém, no tratamento com exportação do tecido vegetal verificam-se valores inversos entre produção de matéria seca e extração de N pela planta. Nessa adubação, a concentração média no tecido vegetal foi de 16,8, 14,1 e 13,0 $\mathrm{g} \mathrm{kg}^{-1}$ respectivamente, nos Sistemas I, II e III. Essa característica deve-se, provavelmente, à composição botânica e aos teores no solo. A correlação entre extração e produção de matéria seca foi significativa e equivalente a 0,83 .

As extrações de $\mathrm{N}$ neste experimento variaram de $74 \mathrm{a} 134 \mathrm{~kg} \mathrm{ha}^{-1}$. Malavolta et al. (1986) e Fageria et al. (1991) apresentam extrações de até 570 e $890 \mathrm{~kg} \mathrm{ha}^{-1}$ respectivamente, em plantas forrageiras. Haag \& Dechen (1994) mostram extrações máximas e mínimas equivalentes a 14 e $640 \mathrm{~kg} \mathrm{ha}^{-1} \mathrm{em}$ gramíneas e leguminosas forrageiras.

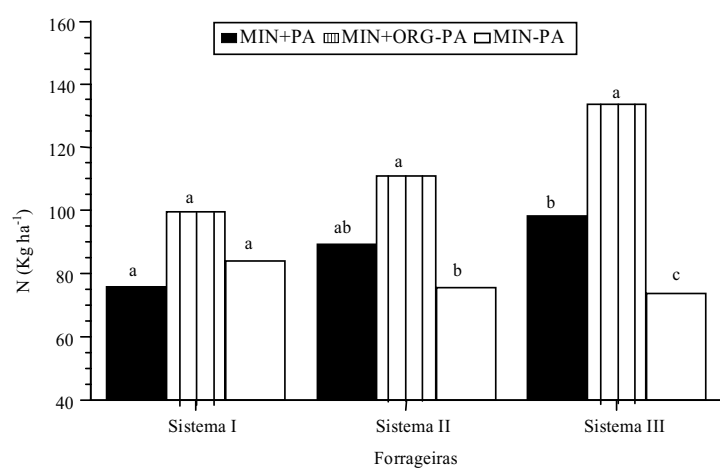

FIG. 7. Efeito das adubações e forrageiras na extração de $N$ pela planta. Período maio/94 a maio/95. (Médias seguidas da mesma letra dentro de cada sistema forrageiro não diferem significativamente pelo teste de Tukey a $5 \%$ de probabilidade).
Com relação à incorporação de $\mathrm{C}$ pela planta (Figs. 5 e 6) observa-se um comportamento semelhante à produção de matéria seca. A correlação entre eles é de 0,99 .

\section{CONCLUSÕES}

1. As maiores produções de matéria seca total ocorrem nas forrageiras dos Sistemas II e III, com adubação orgânica e com permanência da parte aérea.

2. A extração de $\mathrm{K}, \mathrm{Ca}, \mathrm{Mg}, \mathrm{P}$ e N pela planta, com exceção do K no Sistema II e do Ca no Sistema I, é superior no tratamento com adubação orgânica; a extração de K no Sistema II e de Ca no Sistema I é maior na adubação com permanência e com exportação da parte aérea, respectivamente.

3. Os sistemas de maior produção de matéria seca apresentaram maior extração de $\mathrm{Ca}, \mathrm{Mg}$ e $\mathrm{N}$, com exceção do $\mathrm{Ca}$ e do $\mathrm{N}$ na adubação com exportação da parte aérea, em que o Sistema I mostra os maiores resultados; a extração de $\mathrm{K}$ é superior no Sistema II, em todas as adubações.

\section{REFERÊNCIAS}

ANDRADE, L.A.B.L. de. Associação micorrízica e matéria orgânica no crescimento de Brachiara decumbens em estéril de mineração de ferro e bauxita. Viçosa : UFV, 1991. 48p. Dissertação de Mestrado.

FAGERIA, N.K.; BALIGAR, V.C.; JONES, C.A. Growth and mineral nutrition of field crops. New York : M. Dekker, 1991. 476p.

FAVARETTO, N.; MORAES, A. de; MOTTA, A.C.V.; PREVEDELLO, B.M.S. Efeito da revegetação e adubação de área degradada na fertilidade do solo e nas características da palhada. Pesquisa Agropecuária Brasileira, Brasília, v.35, n.2, p.289-297, fev. 2000

HAAG, H.P.; DECHEN, A.R. Deficiências minerais em plantas forrageiras. In: PEIXOTO, A.M.; MOURA, J.C. de; FARIA, V.P. de. (Eds.). Pastagens: fundamentos da exploração racional. 2.ed. Piracicaba : FEALQ, 1994. p.85-110.

HILDEBRAND, C. Manual de análise química de solos e plantas. Curitiba : UFPR, 1977. 225p.

Pesq. agropec. bras., Brasília, v.35, n.2, p.299-306, fev. 2000 
LUCCHESI, L.A.C. Influência de sucessões de culturas forrageiras e adubações sobre a recuperação de um solo degradado pela mineração do xisto e sobre sua mesofauna edáfica (Acari e Collembola). Curitiba : UFPR, 1988. 252p. Dissertação de Mestrado.

MACHADO, M.L. da; MACHADO, N.M. Forrageiras perenes de pique de crescimento na estação quente. In: IAPAR (Londrina, PR). Forrageiras para o primeiro planalto do Paraná. Londrina, 1982. p.19-23. (Circular, 26).

MALAVOLTA, E.; LIEM, T.H.; PRIMAVESI, A.C.P.A. Exigências nutricionais das plantas forrageiras. In: MATTOS, H.B.; WERNER, J.C.; YAMADA, T.; MALAVOLTA, E. (Eds.). Calagem e adubação de pastagens. Piracicaba : Associação Brasileira para a Pesquisa da Potassa e do Fosfato, 1986. p.31-76.

MALAVOLTA, E.; VITTI, G.C.; OLIVEIRA, S.A. Avaliação do estado nutricional das plantas: princípios e aplicações. Piracicaba : Associação Brasileira para a Pesquisa da Potassa e do Fosfato, 1989. 201p.

MEDEIROS, J.C.; MIELNICZUK, J.; PEDO, F. Sistemas de culturas adaptadas à produtividade, recuperação e conservação do solo. Revista Brasileira de Ciência do Solo, Campinas, v.11, p.199-204, 1987.
MELO, E.F.R.Q. Recuperação de área degradada da Itaipu Binacional com forrageiras e adubações. Foz do Iguaçu : CNPq/Itaipu Binacional, 1994. 159p.

MENGEL, K.; KIRKBY, A.E. Principles of plant nutrition. 4.ed. Bern : International Potash Institute, 1987. $687 \mathrm{p}$.

MOTTA NETO, J.A. Avaliação do uso de forrageiras e de adubações na recuperação de propriedades químicas e físicas de um solo degradado pela mineração do xisto. Curitiba : UFPR, 1995. 83p. Dissertação de Mestrado.

POSTIGLIONI, S.R. Efeito do nitrogênio mineral e leguminosas sobre a produção forrageira de quatro gramíneas subtropicais. Londrina : IAPAR, 1985. 18p. (IAPAR. Boletim técnico, 17).

SÁ, J.P.G. Avaliação de forrageiras de inverno no norte do Paraná. Londrina : IAPAR, 1984. 39p. (Informe de Pesquisa, 54).

SPEARS, J.W. Minerals in forages. In: FAHEY JUNIOR, G.C.; COLLINS, M.; MERTENS, D.M.; MOSER, L.E. (Eds.). Forage quality, evaluation, and utilization. Madison : American Society of Agronomy, 1994. p.281-317.

TEDESCO, M.J.; WOLKWEISS, S.J.; BOHNEM, H. Análises de solo, plantas e outros materiais. Porto Alegre : UFRGS, 1985. 188p. (UFRGS. Boletim técnico, 5). 